\title{
An agent to improve gastrointestinal recovery after laparoscopic cholecystectomy: Nicotine gum
}

\author{
Yalın İşcan, ${ }^{1}$ ๑ İksan Taşdelen, ${ }^{2}$ ๑ Yetkin Özcabı, ${ }^{2}$ ๑ Engin Ölçücüoğlu, ${ }^{3}$ ๑ Birol Ağca, ${ }^{2}$

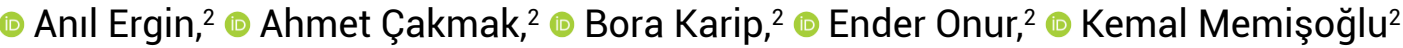 \\ 'Department of General Surgery, Istanbul University, İstanbul Faculty of Medicine, İstanbul, Turkey \\ ${ }^{2}$ Department of General Surgery, University of Health Sciences, Fatih Sultan Mehmet Training and Research Hospital, İstanbul, Turkey \\ ${ }^{3}$ Department of General Surgery, University of Health Sciences, Dışkapı Yıldırım Beyazıd Training and Research Hospital, Ankara, Turkey
}

\begin{abstract}
Introduction: This study aims to investigate the gastrointestinal recovery effects of the nicotine gum after laparoscopic cholecystectomy.

Materials and Methods: In this study, 119 patients were randomized into three groups as follows: Sugarfree gum, nicotine gum and control. After laparoscopic cholecystectomy, within an interval of two hours, the gum was chewed for 15 minutes by the gum groups. Demographic features, postoperative first flatus time, first hunger feelings, first defecation time, constipation scores, smoking, and drain usage were recorded.

Results: The first flatus time of the Nicotine Gum group was significantly lower than those of the Control group $(p=0.018)$. There was no statistically significant difference between the Sugar-Free Gum and the control group $(p=0.992)$. The nicotine gum group was the first to have defecation in a significantly shorter period than the other two groups $(p=0.036, p=0.008, p<0.05)$. According to smoking in all patients, the first flatus time was found to be significantly lower in smokers than in non-smokers $(p=0.004)$. The findings showed that the time of the first defecation was statistically significantly earlier in the smoker patient group $(p=0.015)$.

Conclusion: Nicotine gum used as a sham feeding after laparoscopic cholecystectomy accelerated the recovery of the gastrointestinal system motility. Also, independently of sham feeding, the time of first postoperative gas and defecation were found to have occurred in the earlier period in the patient group of smokers. Keywords: Nicotine gum; postoperative gastrointestinal recovery; sham feeding.
\end{abstract}

\section{Introduction}

One of the most important clinical follow-up criteria after abdominal surgery is the recovery of intestinal functions and early onset of oral intake. ${ }^{[1]}$ Temporary gastrointestinal motility inhibition arising with postoperative nausea, vomiting, abdominal swelling and inability of degassification and defecation symptoms is defined as postoperative ileus (POI). ${ }^{[2]}$ This condition does not completely resolve before 4 days after surgery in $50 \%$ of the patients, and if it persists, it is called prolonged POI (PPOI). ${ }^{[3]} \mathrm{POI}$ increases the hospital cost by prolonging hospital stay and causing hospital-acquired infections, deep vein thrombosis, and pulmonary complications. In the United States, it is the most common cause of prolonged hospital stay after ab-

Received: 16.04.2019 Accepted: 04.05.2020

Correspondence: Yalın İşcan, M.D., Department of General Surgery, Istanbul University,

İstanbul Faculty of Medicine, İstanbul, Turkey

e-mail: yaliniscan@gmail.com 
dominal surgery and is estimated to cost approximately $\$$ 1 billion annually. ${ }^{[4-5]}$

When POI pathophysiology was examined, it was found to be based on multifactorial factors. ${ }^{[6]}$ It has been observed during the surgery that the manipulation of intestines affects the local inflammatory response and generalized intestinal hypomotility. ${ }^{[7]}$ The opiate use after anesthesia and surgery is another important factor that negatively affect motility. ${ }^{[8]}$ The cholinergic anti-inflammatory pathway affects the entire intestinal mechanism via the vagus. In this pathway, nicotinic acetylcholine receptors play an important role and nicotine is the main regulator of this mechanism..$^{[9,10]}$

Epidural anesthesia, early oral intake, early mobilization and laxatives are recommended as a multimodal approach in preventing POI. ${ }^{[11]}$ Chewing gum, a model of sham feeding, has proved its benefits in postoperative intestinal recovery in patients without early oral intake. Multiple meta-analyses and reviews have published the positive effects of chewing gum on the intestinal motility as a sham feeding after abdominal surgery. ${ }^{[12-13]}$

After recognizing the clinical benefits of chewing gum, it has been suggested that it will have a positive effect on the intestinal motility in two different pathways with the combination of nicotine. The first pathway has been hypothesized as the stimulation of cephalo-vagal reflex by chewing gum and the second pathway as the activation of cholinergic anti-inflammatory pathway by nicotine. ${ }^{[14]}$ However, in the first randomized study in colorectal cancer patients, it has been reported that the nicotine gum is feasible but ineffective on bowel motility. ${ }^{[15]}$

As opposed to most previous studies, the aim of our study was to investigate the gastrointestinal recovery effect of nicotine gum after laparoscopic cholecystectomy, in which the intestinal manipulation is minimal and no major abdominal intervention such as laparotomy or gastrointestinal resection is performed.

\section{Materials and Methods}

This study was planned for the duration of 3 months with prospective randomized two studies and one control group in Istanbul Fatih Sultan Mehmet Training and Research Hospital. The approval for this study was obtained by the Ethics Committee of the same hospital with the registration number FSMEAH-KAEK 2017/11. It was carried out in accordance with the World Health Organization
Declaration of Helsinki. ${ }^{[16]}$ CONSORT checklist and a flow diagram were used during the work flow. ${ }^{[17]}$

Patients scheduled for elective laparoscopic cholecystectomy with diagnosis of symptomatic cholelithiasis in the hepatobiliary surgery outpatient clinic were included in the study. Those with ASA 4 or known cardiac disease were excluded from the study. Patients who had postoperative complications after being included in the study were also excluded from the study. The detailed written and oral information was provided to the patient and consent forms were signed for the study. In addition, information was given about the nicotine gum, and all patients were made to chew the nicotine gum before the study. FALIM sugar-free mastic gum (Mondelēz International, Gebze, Turkey) and Nicorette Nicotine Gum Fresh Mint $2 \mathrm{mg}$ (Johnson \& Johnson, Helsingborg, Sweden) were used. The patients were randomized into three groups by sealed envelope method: Nicotine Gum group, Sugar-Free Gum group and control group.

After sealed envelope randomization, all patients underwent the conventional 4-port laparoscopic cholecystectomy. All surgeries were performed by surgeons who perform more than 100 laparoscopic cholecystectomy/year. One drain was placed through the cholecystectomy site and taken out from the lateral $5 \mathrm{~mm}$ port site. All patients were admitted to the hospital on the morning of surgery and discharged on the first postoperative day. The standard analgesia and antiemetic therapy were applied to all patients, for high risk patients deep vein thrombosis was applied. No prophylactic antibiotherapy was used.

Patients who had 9 points and above according to the modified Aldrete's scoring system during staying in the recovery room after the surgery, were taken from the recovery room to the bed. The gums according the groups were prepared by nurse on bed side. After full wakefulness of the patients having the follow-ups on an hourly basis (vital findings were in normal borderline, full orientation of place and direction, no nausea and easy swallowing reflex), within interval of 2 hours the gum was chewed for 15 minutes by the Nicotine Gum group and the Sugar-Free Gum group. The oral intake started 6 hours after the surgery. Chewing gum periods were terminated after the first defecation.

Data records were obtained at the bedside by the general surgery specialists or residents. The drain presence, operation time, first hunger sensation, first flatus and defeca- 
tion times were recorded during the follow-ups. After the discharge, the patients informed the study team by telephone about the first postoperative defecation. Age, sex, body mass index (BMI, $\mathrm{kg} / \mathrm{m}^{2}$ ), constipation scores (Cleveland Clinic Constipation Scoring System) and smoking were added to the study database prior to surgery.

In determining the number of patients for the study, 90 patients were determined to obtain $80 \%$ strength with $0.05 \alpha$ level. Considering an estimated patient loss of $20 \%$, patient recruitment to the study was increased.

\section{Statistical Analysis}

The NCSS (Number Cruncher Statistical System), 2007 \& PASS (Power Analysis and Sample Size), 2008 Statistical Software (Utah, USA) program were used for the statistical analysis. While evaluating the data obtained during the study, apart from using descriptive statistical methods (Mean, Standard Deviation, Median, Frequency, Rate, Minimum, Maximum), the Mann Whitney U test was used to compare two groups, the parameters of which did not show the normal distribution in comparison of quantitative data. Meanwhile, Kruskal Wallis test was used in the comparison of three and above groups with no normal distribution, and the Mann Whitney U test was used to determine the group causing the difference. The Pearson's Chi-square test was used in the comparison of qualitative data. The significance was evaluated at $\mathrm{p}<0.01$ and $\mathrm{p}<0.05$ levels.

\section{Results}

This study was conducted with 140 patients for whom the elective laparoscopic cholecystectomy was planned were informed about the study. Ten patients were excluded from study due to detecting ASA 4 and 4 patients were excluded from the study due to ischemic cardiac disease. The rest of 126 patients were randomized into 3 groups by sealed envelope method on the morning of surgery. There were 45 patients in the control group, 36 in the Sugar-Free Gum group and 45 in the Nicotine Gum group. The laparoscopic cholecystectomy had been planned for all patients; however, the laparoscopic procedure of 3 patients of the Sugar-Free Gum group was turned into the open surgery. Two patients in the Nicotine Gum group and one patient in the SugarFree Gum group could not tolerate to chew the chewing gum after the surgery. On the first postoperative day, one patient in the Sugar-Free Gum group had biliary fistula and suspected pulmonary embolism. Afterwards, upon this, a total of 119 patients ( 45 patients in the control group, 31 patients in the Sugar-Free Gum group and 43 patients in the Nicotine Gum group) were included in the study (Fig. 1).

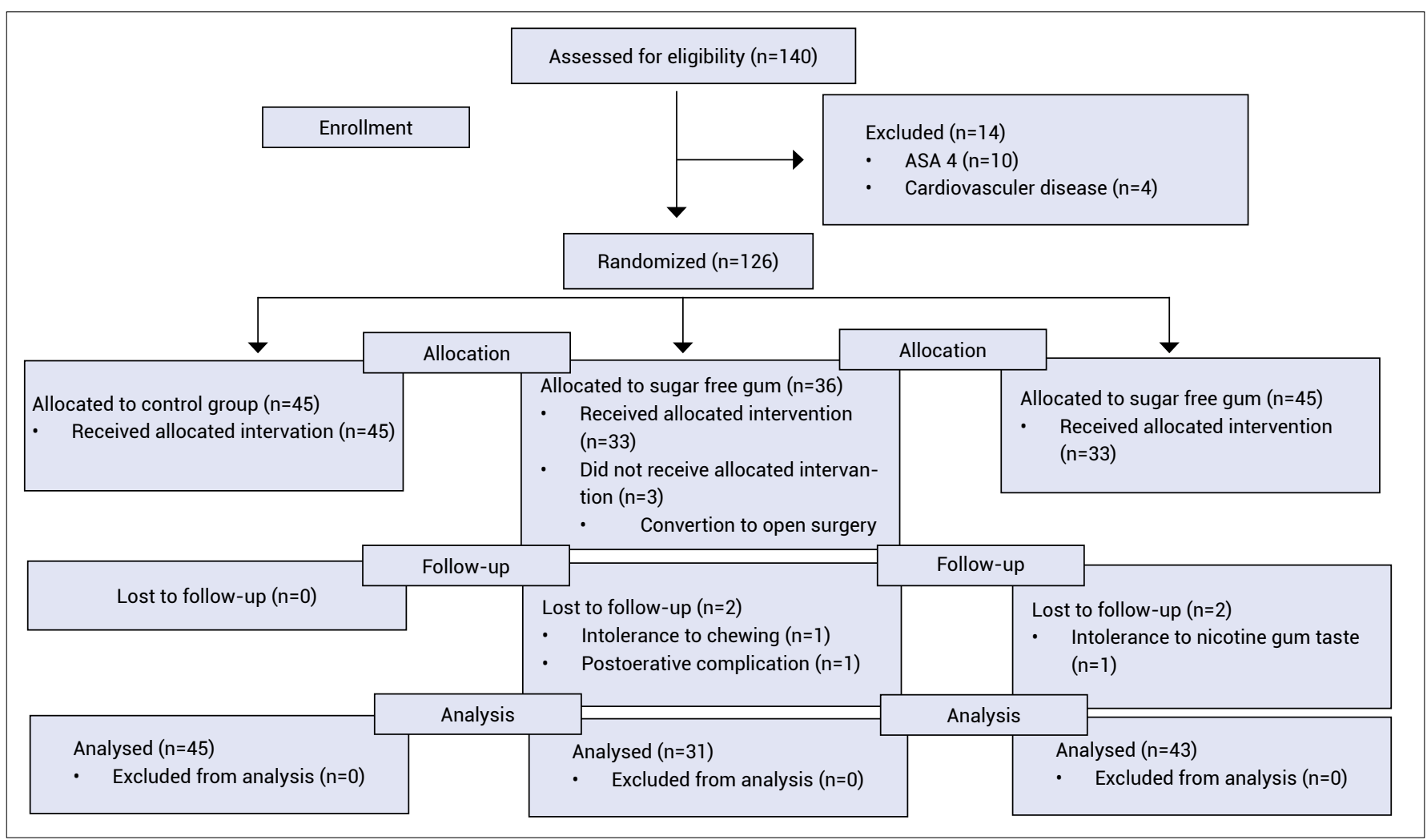

Figure 1. CONSORT diagram. 
When three groups were examined, it was observed that they were similar in terms of age, gender distribution, BMI, and the operation time (Table 1).

There was no statistically significant difference between three groups $(\mathrm{p}=0.247)$ in pre-operative constipation scoring that was checked in order to ensure that the defecation times were homogeneous in patient groups (Table 2).

There was a statistically significant difference in the patients' first hunger feelings between the groups ( $p=0.017$; $\mathrm{p}<0.05$ ). The bilateral comparison was made to identify the group that created the difference. The first fasting measure of the Nicotine Gum group was significantly lower than in the control group $(\mathrm{p}=0.005 ; \mathrm{p}<0.01)$. However, no significant difference in the first fasting measure was observed between the Nicotine Gum group and the Chewing Gum group ( $\mathrm{p}=0.288 ; \mathrm{p}=0.112 ; \mathrm{p}>0.05$ ) (Table 2).

A statistically significant difference was found between gas discharge times $(\mathrm{p}=0.021, \mathrm{p}<0.05)$ (Table 3$)$. In the bilateral comparisons, the first flatus time of the Nicotine Gum group were significantly lower than those of the control group ( $\mathrm{p}=0.018, \mathrm{p}=0.016, \mathrm{p}<0.05)$. There was no statistically significant difference between the Sugar-Free Gum

\section{Table 1. Baseline patient characteristics and operation time in groups}

\begin{tabular}{lcccc} 
& Control $(\mathbf{n}=\mathbf{4 5})$ & Sugar-free gum $(\mathbf{n}=\mathbf{3 1})$ & Nicotine gum $(\mathbf{n}=\mathbf{4 3})$ & $\mathbf{p}$ \\
\hline Age (years) & $43.1 \pm 10.42$ & $46.4 \pm 12.18$ & $45.9 \pm 15.83$ & 0.768 \\
Sex & & & & \\
$\quad$ Male & 15 & 10 & 14 & 0.69 \\
$\quad$ Female & 0 & 21 & 29 & 0.964 \\
BMI $\left(\mathrm{kg} / \mathrm{m}^{2}\right)$ & $29.00 \pm 5.67$ & $32.20 \pm 8.34$ & $28.42 \pm 6.47$ & 0.842 \\
Operation time & $60.24 \pm 10.34$ & $54.32 \pm 20.16$ & $58.10 \pm 18.36$ &
\end{tabular}

Table 2. Postoperative clinical outcomes of the study groups

\begin{tabular}{lcccc} 
& Control $(\mathbf{n}=\mathbf{4 5})$ & Sugar-free gum $(\mathbf{n = 3 1})$ & Nicotine gum $(\mathbf{n}=\mathbf{4 3})$ & $\mathbf{p}$ \\
\hline First flatus $(\mathrm{h})$ & $13.89 \pm 9.12$ & $13.81 \pm 7.85$ & $9.31 \pm 3.83$ & $0.021 *$ \\
First hunger $(\mathrm{h})$ & $8.40 \pm 7.99$ & $5.77 \pm 2.91$ & $4.74 \pm 2.33$ & $0.017 *$ \\
First defecation $(\mathrm{h})$ & $36.89 \pm 19.91$ & $37.61 \pm 20.43$ & $29.52 \pm 22.87$ & $0.019 *$ \\
Cons. score & $2.73 \pm 3.35$ & $3.32 \pm 3.85$ & $2.14 \pm 3.10$ & 0.247 \\
\hline
\end{tabular}

Kruskal wallis test; * $\mathrm{p}<0.05$.

Table 3. Smoking and drain use in groups

\begin{tabular}{|c|c|c|c|c|c|c|c|}
\hline & \multicolumn{2}{|c|}{$\begin{array}{l}\text { Control } \\
(n=45)\end{array}$} & \multicolumn{2}{|c|}{$\begin{array}{l}\text { Sugar-free gum } \\
\qquad(n=31)\end{array}$} & \multicolumn{2}{|c|}{$\begin{array}{l}\text { Nicotine gum } \\
\qquad(n=43)\end{array}$} & \multirow[t]{2}{*}{$\mathbf{p}$} \\
\hline & $\mathbf{n}$ & $\%$ & $\mathbf{n}$ & $\%$ & $\mathbf{n}$ & $\%$ & \\
\hline \multicolumn{8}{|c|}{ Smoking } \\
\hline$(-)$ & 36 & 80.0 & 23 & 74.2 & 32 & 74.4 & 0.778 \\
\hline$(+)$ & 9 & 20.0 & 8 & 25.8 & 11 & 25.6 & \\
\hline \multicolumn{8}{|l|}{ Drain } \\
\hline$(-)$ & 24 & 53.3 & 14 & 45.2 & 24 & 55.8 & 0.649 \\
\hline$(+)$ & 21 & 46.7 & 17 & 54.8 & 19 & 44.2 & \\
\hline
\end{tabular}


group and the control group ( $\mathrm{p}=0.992 ; \mathrm{p}>0.05)$ (Table 2$)$.

When the first defecation times of the groups were investigated, a statistically significant difference was found $(\mathrm{p}=0.019 ; \mathrm{p}<0.05)$ (Table 2). The group using nicotine gum was the first to have defecation in a significantly shorter period than the other two groups $(p=0.036$, $\mathrm{p}=0.008, \mathrm{p}<0.05)$. There was no statistically significant difference $(p=0.975, p>0.05)$ when the sugar free gum group and the control group were compared in terms of first defecation time.

There was no statistically significant difference when all groups were compared among themselves in terms of smoking and drain use $(p>0.05, p>0.05)$ (Table 3$)$.

Smoking among the groups was analyzed as a subgroup analysis. In the 3 groups, two subgroups were created as smoker and non-smoker. These subgroups were compared in themselves in terms of first feeling of hunger, first flatus and first defecation times. There was no statistically significant difference between the first feeling of hunger, first flatus and first defecation values according to the subgroup analyses done in the three groups (Table 4).

All the patients were divided into two groups according to smoking status. Smoker $(n=28)$ and non-smoker pa- tients ( $\mathrm{n}=91)$ were compared in terms of first feeling of hunger, first gas and first defecation times. According to smoking, there was no statistical difference between the first feeling of hunger measurements in patients ( $p>0.05$ ). The first flatus time was found to be significantly lower in smokers than in non-smokers $(\mathrm{p}=0.004 ; \mathrm{p}<0.01)$. Similar results were also found in the first defecation time. It was found that the time of first defecation was statistically significantly earlier in the smoker patient group $(\mathrm{p}=0.015$, $\mathrm{p}<0.05$ ) (Table 5).

In order to assess the effect of drain use, patients were divided into two groups as using drain and not using drain. In this investigation, it was found that the first gas and defecation time were statistically significantly higher in the patients using drain $(\mathrm{p}=0.016, \mathrm{p}=0.038$, respectively; $\mathrm{p}<0.05$ ) (Table 6).

\section{Discussion}

POI is commonly experienced after major abdominal surgery. ${ }^{[18]}$ This may prolong the length of patient's hospital stay and may lead to life-threatening complications. ${ }^{[4-5]}$ Although multiple effective proactive measures have been defined to prevent POI, a certain treatment has not yet been determined due to its certain multifactorial pathophysiol-

Table 4. Smoking analyses in the groups

\begin{tabular}{|c|c|c|c|}
\hline Control group & $\begin{array}{l}(-)(n) \\
n=36\end{array}$ & $\begin{array}{l}\text { Smoking } \\
\begin{array}{c}(+)(n) \\
n=9\end{array}\end{array}$ & p \\
\hline First flatus (h) & $14.78 \pm 9.76$ & $10.33 \pm 4.77$ & 0.177 \\
\hline First hunger (h) & $8.42 \pm 8.79$ & $8.33 \pm 3.64$ & 0.165 \\
\hline First defecation (h) & $39.19 \pm 20.16$ & $27.67 \pm 16.81$ & 0.091 \\
\hline Cons. score & $2.42 \pm 3.33$ & $4.00 \pm 3.28$ & 0.114 \\
\hline Sugar-free gum & $n=23$ & $n=8$ & \\
\hline First flatus (h) & $15.13 \pm 8.54$ & $10.00 \pm 3.59$ & 0.102 \\
\hline First hunger (h) & $5.83 \pm 3.26$ & $5.63 \pm 1.69$ & 0.964 \\
\hline First defecation (h) & $42.17 \pm 21.81$ & $24.50 \pm 5.48$ & 0.074 \\
\hline Cons. score & $3.22 \pm 3.69$ & $3.63 \pm 4.53$ & 0.851 \\
\hline Nicotine gum & $n=32$ & $n=11$ & \\
\hline First flatus (h) & $10.69 \pm 4.78$ & $7.55 \pm 3.01$ & 0.067 \\
\hline First hunger (h) & $5.56 \pm 3.52$ & $4.27 \pm 1.79$ & 0.254 \\
\hline First defecation (h) & $30.75 \pm 24.95$ & $24.55 \pm 12.53$ & 0.540 \\
\hline Cons. score & $2.03 \pm 3.13$ & $2.27 \pm 3.10$ & 0.768 \\
\hline
\end{tabular}


Table 5. Clinical outcomes according to smoking

\begin{tabular}{lccc} 
& Smoking & p \\
& $(-)(\mathbf{n = 9 1 )}$ & $(+)(\mathbf{n = 2 8 )}$ & $0.004 * *$ \\
\hline First flatus $(\mathrm{h})$ & $13.43 \pm 8.18$ & $9.14 \pm 3.89$ & 0.922 \\
First hunger $(\mathrm{h})$ & $6.76 \pm 6.22$ & $5.96 \pm 2.99$ & $0.015^{\star}$ \\
First defecation $(\mathrm{h})$ & $36.98 \pm 22.62$ & $25.54 \pm 12.32$ & 0.290 \\
Cons. score & $2.48 \pm 3.35$ & $3.21 \pm 3.56$ & \\
\hline Mann whitney u test; $*$ * $<0.01 ; * \mathrm{p}<0.05$. & & &
\end{tabular}

Table 6. Clinical outcomes according to drain use

\begin{tabular}{lccc} 
& & Drain Use & p \\
& $(-)(\mathbf{n = 6 2 )}$ & $(+)(\mathbf{n = 5 7 )}$ & $0.016^{*}$ \\
\hline First flatus $(\mathrm{h})$ & $11.00 \pm 6.88$ & $13.96 \pm 8.10$ & 0.586 \\
First hunger $(\mathrm{h})$ & $6.34 \pm 6.03$ & $6.82 \pm 5.20$ & $0.038^{*}$ \\
First defecation $(\mathrm{h})$ & $29.71 \pm 15.91$ & $39.26 \pm 24.92$ & 0.200 \\
Cons. score & $2.97 \pm 3.47$ & $2.32 \pm 3.32$ & \\
\hline Mann whitney u test; $* \mathrm{p}<0.05$. & & &
\end{tabular}

ogy. ${ }^{[2]}$ It has been published in numerous reviews that postoperative sham feeding and chewing gum stimulated the gastrointestinal motility through the vagal pathways by mimicking the cephalic phase of digestion, however, there are also studies that do not support these evidences. ${ }^{[19]}$

Positive effects of nicotine on the recovery of the gastrointestinal system have been reported in conducted animal experiments. ${ }^{[9]}$ It has been hypothesized that the association of chewing gum and nicotine may stimulate the physiological pathways by chewing through vagus, while activating the pharmacological pathways by nicotine intake. ${ }^{[14]}$ However, in the first clinical trial conducted on patients undergone colorectal surgery, this hypothesised positive effect of nicotine gum was not found. ${ }^{[15]}$

In the previous studies using chewing gum as a sham feeding, the case series of major abdominal surgery and colorectal resection have generally been employed. ${ }^{[13]}$ It is clearly stated in the literature that these interventions are the most important factors of POI. ${ }^{[20]}$ We think that studies conducted with the main factors in this multifactorial clinical condition will not provide healthy data. We planned to investigate the postoperative effects of sugarfree gum and nicotine gum on the gastrointestinal system in laparoscopic cholecystectomy patients with minimal abdominal trauma.

It is known that colonic dysfunction is one of the important causes of postoperative ileus. ${ }^{[21]}$ When the preoperative constipation scores were investigated in our study, no statistical difference was found among all groups. Thus, we believe that we evaluated the gastrointestinal motility of all groups in a more healthy way.

In a study of Lonescu et al. ${ }^{[22]}$ conducted on laparoscopic cholecystectomy patients, it has been shown that postoperative nicotine band application significantly reduced postoperative nausea and vomiting. In our study, it was found that the first feeling of hunger was statistically gained in a shorter period of time among all groups of nicotine gum. We think that this is caused by the fact that postoperative stomach motility improved faster, leading to the feeling of nausea and vomiting. It was also observed that the first feeling of hunger of the nicotine gum group was shorter than that of the sugar-free gum group, but no statistical significance was found.

In a prospective randomized study of 149 patients who underwent pelvic and paraaortic lymphadenectomy along with total abdominal hysterectomy, Ertas et al. ${ }^{[23]}$ have found that the sugar-free gum had a positive effect on the intestinal movements, and that oral intake-gas and 
stool discharge were faster than that of the control group. When the first gas discharge and defection times were evaluated in our study, it was found that only the nicotine gum statistically significantly reduced the passage time, and that the control group of the Sugar-Free Gum group did not establish such superiority. The positive effect of sham feeding on gastrointestinal recovery in the literature was not found in our study. ${ }^{[13]}$ Since nicotine is an essential regulator in the cholinergic anti-inflammatory pathway and due to its positive effect on the intestinal motility which was previously proved in animal experiment, ${ }^{[9]}$ we think that we only got positive results in the nicotine gum group in our study.

In a series of 355 patients undergone different elective surgeries (breast prosthesis implantation, inguinal hernia and arthroscopy), it has been shown that being a smoker had a positive effect on postoperative nausea and vomiting. ${ }^{[24]}$ In a review questioning why nicotine prevents nausea and vomiting, it has been stated that anesthetic substances were broken down by the CYP2E1 enzyme in the liver and this enzyme was induced by nicotine. Therefore, it has been suggested that the anesthetic substances broke down faster in smokers and the negative effects on the gastrointestinal system disappeared more quickly. ${ }^{[25]}$ When all patients in our study are divided into two groups according to being smoker, the duration of first gas and defecation was significantly shorter in smokers, but this has not been reflected on the first feeling of hunger. There was no difference between the two groups in terms of first feeling of hunger.

To be able to see the effect of drain use, the entire patient group was divided into two groups according to their drain use. It was found that gas and stool discharge was statistically significantly later in patients using drains. When the literature is reviewed, it has been seen that drain use increased the abdominal inflammation and secondary to that, complications occurred. ${ }^{[26,27]}$ As a conclusion of our study, we think that intra-abdominal drain triggered the inflammatory process and negatively affected the recovery of the gastrointestinal system.

\section{Conclusion}

In our small patient numbered clinical study, we observed that nicotine gum used as a pseudo-nutrition after laparoscopic cholecystectomy accelerated the recovery of the gastrointestinal system motility. Also, independently of pseudo-nutrition, the time of first postoperative gas and defecation was found to have occurred in the earlier period in the patient group of smokers. In accordance with numerous studies, we have also seen the positive effect of nicotine on the intestinal motility; however, better results can be obtained in prospective studies on major abdominal surgery with different doses or different forms of administration such as nicotine bands or sprays.

\section{Disclosures}

Ethichs Committee Approval: The approval for this study was obtained by the Ethics Committee of Istanbul Fatih Sultan Mehmet Training and Research Hospital with the registration number FSMEAH-KAEK 2017/11.

Peer-review: Externally peer-reviewed.

Conflict of Interest: None declared.

Authorship Contributions: Concept - Y.I., B.K.; Design - Y.I., I.T.; Supervision - K.M.; Materials - Y.Ö., E.Ö., Y.I.; Data collection and/or processing - I.T., A.E., A.Ç.; Analysis and/or interpretation - B.K., Y.I.; Writing - Y.I., B.A.; Critical review - E.O., K.M.

\section{References}

1. Sun DL, Li WM, Li SM, Cen YY, Xu QW, Li YJ, Sun YB, Qi YX, Lin YY, Yang T, Lu QP. Comparison of multi-modal early oral nutrition for the tolerance of oral nutrition with conventional care after major abdominal surgery: a prospective, randomized, single-blind trial. Nutrition Journal 2017;16:11.

2. Gero D, Gié O, Hübner M, Demartines N, Hahnloser D. Postoperative ileus: in search of an international consensus on definition, diagnosis, and treatment. Langenbeck's Arch Surg 2016;402:149-58. [CrossRef]

3. Wolff BG, Michelassi F, Gerkin TM, Techner L, Gabriel K, DuW, et al. Alvimopan, a novel, peripherally acting mu opioid antagonist: results of a multicenter, randomized, double-blind, placebo-controlled, phase III trial ofmajor abdominal surgery and postoperative ileus. Ann Surg 2004;240:728-34. [CrossRef]

4. Schuster R, Grewal N, Greaney GC, Waxman. Gum chewing reduces ileus after elective open sigmoid colectomy. Arch Surg 2006;141:174-6. [CrossRef]

5. McCormick JT. Gum in the postoperative setting: something to chew on. Dis Colon Rectum 2013;56:273-4. [CrossRef]

6. Luckey A, Livingston E, Tache Y. Mechanisms and treatment of postoperative ileus. Arch Surg 2003;138:206-14. [CrossRef]

7. Kalff JC, Schraut WH, Simmons RL, Bauer AJ. Surgical manipulation of the gut elicits an intestinal muscularis inflammatory response resulting in postsurgical ileus. Ann Surg 1998;228:652-63. [CrossRef]

8. Ogilvy AJ, Smith G. The gastrointestinal tract after anesthesia. Eur J Anaesthesiol Suppl 1995;1035-42.

9. The FO, Boeckxstaens GE, Snoek SA, Cash JL, Bennink R, 
Larosa GJ, et al. Activation of the cholinergic anti-inflammatory pathway ameliorates postoperative ileus in mice. Gastroenterology 2007;133:1219-28. [CrossRef]

10. De Winter BY, Boeckxstaens GE, De Man JG, Moreels TG, Herman AG, Pelckmans PA. Effects of $\mu$ - and $\mathrm{k}$-opioid receptors on postoperative ileus in rats. Eur J Pharmacol 1997;339:637. [CrossRef]

11. Basse L, HjortJakobsen D, Billesbølle P, Werner M, Kehlet H. A clinical pathway to accelerate recovery after colonic resection. Ann Surg 2000;232:51-7. [CrossRef]

12. Vásquez W1, Hernández AV, Garcia-Sabrido JL. J. Is gum chewing useful for ileus after elective colorectal surgery? A systematic review and meta-analysis of randomized clinical trials. Gastrointest Surg 2009;13:649-56. [CrossRef]

13. Liu $Q$, Jiang $H, X u D$, Jin J. Effect of gum chewing on ameliorating ileus following colorectal surgery: A meta-analysis of 18 randomized controlled trials. Int J Surg 2017;47:107-15.

14. Wu Z, Boersema GS, Jeekel J, Lange JF. Nicotine gum chewing: a novel strategy to shorten duration of postoperative ileus via vagus nerve activation. Med Hypotheses 2014;83:352-4.

15. Lambrichts DPV, Boersema GSA, Tas B, Wu Z, Vrijland WW, Kleinrensink GJ, et al . Nicotine chewing gum for the prevention of postoperative ileus after colorectal surgery: a multicenter, double-blind, randomised, controlled pilot study. Int J Colorectal Dis 2017;32:1267-75. [CrossRef]

16. World Medical Association. WMA Declaration of Helsinki Ethical Principles for Medical Research Involving Human Subjectshtips//umwumanet/policies-post/wma-dedaration-of-helsink-ethica-principles-for-medical-research-involving-human-subjects/

17. CONSORT. The CONSORT Statement. http://www.consort-statement.org/

18. Ishizuka M, Shibuya N, Nagata H, Takagi K, Iwasaki Y, Hachiya $\mathrm{H}$, et al. Perioperative Administration of Traditional Japanese Herbal Medicine Daikenchuto Relieves Postoperative Ileus in Patients Undergoing Surgery for Gastrointestinal Cancer: A Systematic Review and Meta-analysis. Anticancer Res 2017;37:5967-74. [CrossRef]

19. Ge B, Zhao H, Lin R, Wang J, Chen Q, Liu L, et al. Influence of gum-chewing on postoperative bowel activity after laparoscopic surgery for gastric cancer: A randomized controlled trial. Medicine (Baltimore) 2017;96:e6501. [CrossRef]

20. Iyer S, Saunders WB, Stemkowski S. Economic burden of postoperative ileus associated with colectomy in the United States. J Manag Care Pharm 2009;15:485-94. [CrossRef]

21. Woods JH, Erickson LW, Condon RE, Schulte WJ, Sillin LF. Postoperative ileus: a colonic problem? Surgery 1978;84:527-33.

22. Ionescu D, Badescu C, Acalovschi I. Nicotine patch for the prevention of postoperative nausea and vomiting a prospective randomised trial. Clin Drug Invest 2007;27:559-64.

23. Ertas IE, Gungorduk K, Ozdemir A, Solmaz U, Dogan A, Yildirim $Y$. Influence of gum chewing on postoperative bowel activity after complete staging surgery for gynecological malignancies: a randomized controlled trial. Gynecol Oncol 2013;131:118-22. [CrossRef]

24. Brattwall $M$, Warrén Stomberg $M$, Rawal $N$, Segerdahl $M$, Houltz E, Jakobsson J. Postoperative impact of regular tobacco use, smoking or snuffing, a prospective multi-center study. Acta Anaesthesiol Scand 2010;54:321-7. [CrossRef]

25. Sweeney BP. Why does smoking protect against PONV? Br J Anaesth 2002;89:810-3. [CrossRef]

26. Weiss $S$, Messner $F$, Huth $M$, Weissenbacher A, Denecke $C$, Aigner $\mathrm{F}$, et al. Impact of abdominal drainage systems on postoperative complication rates following liver transplantation. Eur J Med Res 2015;20:66. [CrossRef]

27. Petrowsky H, Demartines N, Rousson V, Clavien PA. Evidence-based value of prophylactic drainage in gastrointestinal surgery: a systematic review and meta-analyses. Ann Surg 2004;240:1074-85. [CrossRef] 